for any of these conditions at any time of life anywhere in the world. Until this happens, there will still be patients who present with recurrent infections who have undiagnosed, genetically determined immunodeficiency, the basis of which is unidentified. Failure to make these diagnoses early in life results in high rates of mortality and morbidity that could be prevented.

Address correspondence to: Rebecca Buckley, Box 2898, Duke University Medical Center, Durham, North Carolina 27710, USA. Phone: (919) 684-2922; Fax: (919) 681-7979; E-mail: buckL003@mc.duke.edu.

\footnotetext{
1. Bruton, O.C. 1952. Agammaglobulinemia. Pediatrics 9:722-728.

2. Notarangelo, L., et al. 2004. Primary immunodeficiency diseases: an update. J. Allergy Clin. Immunol. 114:677-687.

3. de Villartay, J.-P., et al. 2005. A novel immunodeficiency associated with hypomorphic RAG1 mutations and CMV infection. J. Clin. Invest. 115:3291-3299. doi:10.1172/JCI25178.

4. de Saint-Basile, G., et al. 1991. Restricted heterogeneity of T lymphocytes in combined immunodeficiency with hypereosinophilia (Omenn syndrome). J. Clin. Invest. 87:1352-1359.
}

5. Schwarz, K., et al. 1996. RAG mutations in human B cell-negative SCID. Science. 274:97-99.

6. Villa, A., et al. 1998. Partial V(D)J recombination activity leads to Omenn syndrome. Cell. 93:885-896.

7. Corneo, B., et al. 2001. Identical mutations in RAG1 or RAG2 genes leading to defective $\mathrm{V}(\mathrm{D}) \mathrm{J}$ recombinase activity can cause either T-B-severe combined immune deficiency or Omenn syndrome. Blood. 97:2772-2776.

8. Lindvall, J.M., et al. 2005. Bruton's tyrosine kinase: cell biology, sequence conservation, mutation spectrum, siRNA modifications, and expression profiling. Immunol. Rev. 203:200-215.

9. Wood, P.M., et al. 2001. A mutation in Bruton's tyrosine kinase as a cause of selective anti-polysaccharide antibody deficiency. J. Pediatr. 139:148-151.

10. Jin, Y., et al. 2004. Mutations of the Wiskott-Aldrich Syndrome Protein (WASP): hotspots, effect on transcription, and translation and phenotype/genotype correlation. Blood. 104:4010-4019.

11. Morra, M., et al. 2001. Alterations of the X-linked lymphoproliferative disease gene SH2D1A in common variable immunodeficiency syndrome. Blood. 98:1321-1325

12. Arico, M., et al. 2001. Hemophagocytic lymphohistiocytosis due to germline mutations in SH2D1A, the X-linked lymphoproliferative disease gene. Blood. 97:1131-1133.

13. Soudais, C., De Villartay, J.P., Le Deist, F., Fischer, A., and Lisowska-Grospierre, B. 1993. Independent mutations of the human CD3-epsilon gene resulting in a $\mathrm{T}$ cell receptor/CD3 complex immunodeficiency. Nat. Genet. 3:77-81.

14. de Saint Basile, G., et al. 2004. Severe combined immunodeficiency caused by deficiency in either the $\delta$ or the $\varepsilon$ subunit of CD3. J. Clin. Invest 114:1512-1517. doi:10.1172/JCI200422588.

15. Buckley, R.H. 2004. Molecular defects in human severe combined immunodeficiency and approaches to immune reconstitution. Annu. Rev. Immunol. 22:625-655.

16. Schmalstieg, F.C., et al. 1995. Missense mutation in exon 7 of the common $\gamma$ chain gene causes a moderate form of X-linked combined immunodeficiency. J. Clin. Invest. 95:1169-1173.

17. Hershfield, M.S. 2003. Genotype is an important determinant of phenotype in adenosine deaminase deficiency. Curr. Opin. Immunol. 15:571-577.

18. Frucht, D.M., et al. 2001. Unexpected and variable phenotypes in a family with JAK3 deficiency. Genes Immun. 2:422-432.

19. Ege, M., et al. 2005. Omenn syndrome due to ARTEMIS mutations. Blood. 105:4179-4186.

20. Durandy, A., Revy, P., and Fischer, A. 2004. Human models of inherited immunoglobulin class switch recombination and somatic hypermutation defects (hyper-IgM syndromes). Adv. Immunol. 82:295-330.

21. Buckley, R.H. 2004. The multiple causes of human SCID. J. Clin. Invest 114:1409-1411. doi:10.1172/ JCI200423571.

22. Grimbacher, B., et al. 2003. Homozygous loss of ICOS is associated with adult-onset common variable immunodeficiency. Nat. Immunol. 4:261-268.

23. Salzer, U., et al. 2005. Mutations in TNFRSF13B encoding TACI are associated with common variable immunodeficiency in humans. Nat. Genet. 37:820-828.

\title{
New insights into nNOS regulation of vascular homeostasis
}

\author{
Gregg L. Semenza
}

Vascular Biology Program, Institute for Cell Engineering, Departments of Pediatrics, Medicine, Oncology, and Radiation Oncology, and McKusick-Nathans Institute of Genetic Medicine, The Johns Hopkins University School of Medicine, Baltimore, Maryland, USA.

\begin{abstract}
An important physiological response to changes in local or systemic oxygenation is the modulation of vascular tone, which is mediated in part by changes in the activities of the 3 NO synthase (NOS) isoforms. In arterial smooth muscle cells, acute hypoxia induces increased vascular tone, which is attenuated if hypoxia persists. In this issue of the JCI, Ward et al. demonstrate that changes in $\mathrm{O}_{2}$ concentration have effects on neuronal NOS enzymatic activity and gene expression that contribute to vascular homeostasis under conditions of acute and chronic hypoxia (see the related article beginning on page 3128).
\end{abstract}

Every cell in the human body is dependent upon the delivery of adequate concentrations of $\mathrm{O}_{2}$ to maintain normal cellular functions, which are principally powered by ATP derived from mitochondrial oxi-

Nonstandard abbreviations used: HIF-1, hypoxiainducible factor- 1 ; nNOS, neuronal NOS; NOS NO synthase.

Conflict of interest: The author has declared that no conflict of interest exists.

Citation for this article: J. Clin. Invest. 115:2976-2978 (2005). doi:10.1172/JCI26792. dative phosphorylation. The anatomical matching of $\mathrm{O}_{2}$ delivery to demand is determined by the production of secreted factors that stimulate blood vessel growth, most notably VEGF (1). Every step of its biogenesis, from transcription of $V E G F$ gene sequences in the nucleus and protection of the resulting mRNA against degradation to the ribosomal translation and folding of VEGF protein in the endoplasmic reticulum and transport via the Golgi system to the plasma membrane for secretion, is $\mathrm{O}_{2}$ regulated, as is the expression of its cognate receptor on vascular endothelial cells (1-3).

Anatomical responses to changes in $\mathrm{O}_{2}$ demand occur on a scale of days, whereas other physiological responses resulting in alterations in $\mathrm{O}_{2}$ delivery occur on a scale of seconds. Systemic responses are mediated by chemoreceptor cells in the carotid body that depolarize in response to reduced arterial $\mathrm{O}_{2}$ tension, leading to reflex changes in ventilation, heart rate, and vascular tone (4). The vasculature within tissues also responds to acute regional hypoxia by dilation of arterioles that control the flow of blood into each capillary bed, as in the case of increased $\mathrm{O}_{2}$ consumption in skeletal muscle during exercise (5). In contrast, when systemic hypoxia occurs as a result of vascular hypotension (shock), the adrenergic nervous system directs redistribution of blood flow to maintain the perfusion of 
A

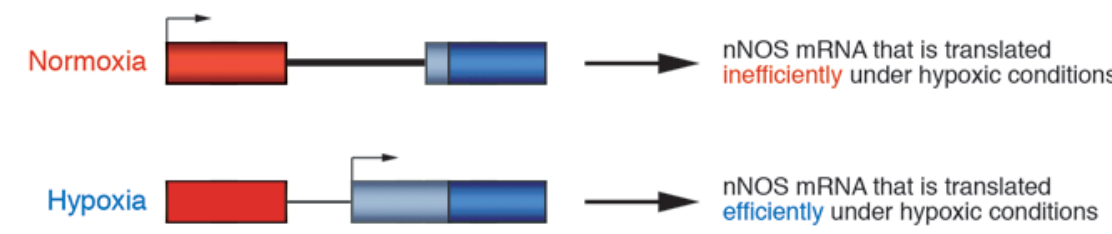

B

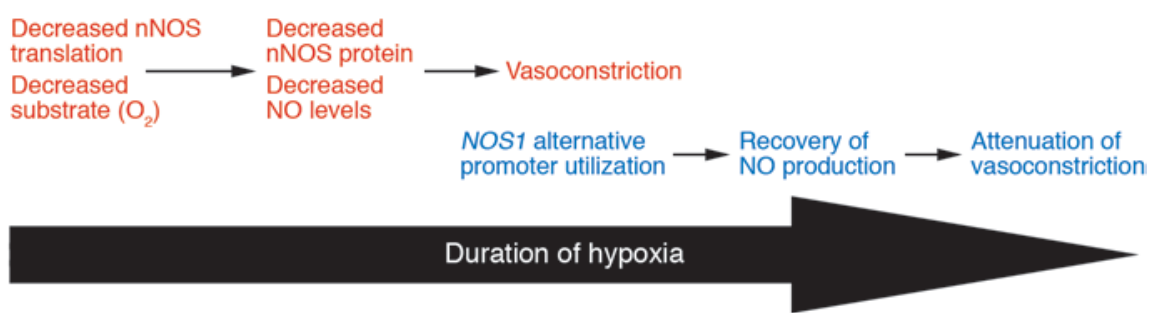

C

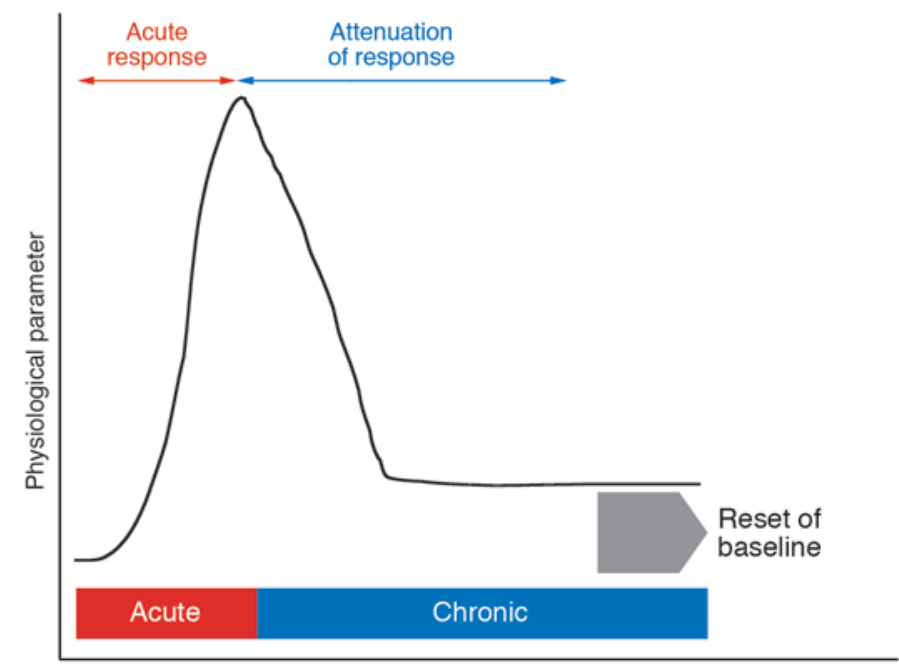

Duration of stimulus

the heart and brain at the expense of other organs such as the gastrointestinal tract. However, under conditions of chronic hypoxia, the contractile response of arteries to hypoxia is blunted in an attempt to maintain tissue viability.

\section{NO business like flow business}

The endothelium plays a critical role in the production of vasoactive molecules that regulate blood flow. NO produced in the endothelium by eNOS (encoded by the NOS3 gene in humans) has been shown to play a major role by binding to soluble guanylate cyclase in vascular smooth muscle cells, resulting in cGMP production and the activation of signal transduction pathways leading to vasodilation (6). Activation of eNOS is also required for endothelial cell responses to angiogenic factors. Under hypoxic conditions, iNOS mRNA (encoded by the human NOS2 gene) is also expressed in endothelial cells, macrophages, and other cell types $(7,8)$.

In this issue of the JCI, Ward et al. report that chronic hypoxia also induces increased activity of neuronal NO synthase (nNOS; encoded by the human NOS1 gene) in arterial smooth muscle cells (9). Increased nNOS activity is a consequence of increased nNOS protein synthesis, which occurs against the background of a global reduction in protein synthesis that serves to conserve ATP by reducing the synthesis of all nonessential proteins in hypoxic cells. A major mechanism mediating inhibition of protein synthesis is the phosphorylation of eukaryotic translation initiation factor- $2 \alpha$ by pancre-

\section{Figure 1}

Oxygen-dependent regulation of nNOS activity and vasomotor tone. (A) Hypoxia-induced transcription of an alternative nNOS mRNA species. The 2 panels depict nNOS mRNA transcription under normoxic (upper) and hypoxic (lower) conditions. In each panel, the mRNA transcription start site is indicated by a bent arrow; $5^{\prime}$-untranslated sequences are indicated by a light blue box; translated sequences are indicated by a dark blue box; intervening sequences are indicated by a thick line; and $5^{\prime}$-flanking sequences are indicated by a thin line. Top panel: Under normoxic conditions, transcription is initiated at exon 1 (red box), which consists of $5^{\prime}$-untranslated sequences. Exon 2 contains additional 5'untranslated sequences (light blue box) and the beginning of the protein coding sequence (dark blue box). Lower panel: In this issue of the $\mathrm{JCl}$, Ward et al. (9) demonstrate that under hypoxic conditions, transcription is initiated downstream of exon 1, resulting in the synthesis of nNOS mRNA containing an alternative $5^{\prime}$-untranslated region (light blue box). Under hypoxic conditions, the translation of mRNA containing exon 1 is inhibited, whereas the alternative mRNA is efficiently translated into protein. Thus, a qualitative change in the structure of nNOS mRNA based upon alternative transcription initiation results in a quantitative change in the levels of nNOS protein synthesized under hypoxic conditions. (B) Time-dependent responses to hypoxia in vascular smooth muscle cells. (C) Attenuation of physiological responses with chronic stimulation. A physiological stimulus (e.g., hypoxia) induces an acute physiological response (e.g., increased vascular tone). However, if the stimulus persists, the response is attenuated, resulting in the establishment of a new (reset) steady state.

atic endoplasmic reticulum kinase (PERK), which inhibits cap-dependent mRNA translation (10). The mRNAs encoding VEGF and several other proteins that are expressed in response to hypoxia contain an internal ribosomal entry site, which provides a mechanism for bypassing the inhibition of capdependent translation (11).

Table 1

Apparent $K_{m}$ of NOSs for $\mathrm{O}_{2}$

\begin{tabular}{lcc}
\hline Gene & Protein & $\boldsymbol{K}_{\boldsymbol{m}}(\boldsymbol{\mu} \mathbf{M})$ \\
NOS1 & nNOS & 350 \\
NOS2 & iNOS & 130 \\
NOS3 & eNOS & 4 \\
\hline
\end{tabular}

Data represented in this table are from ref. 14. 


\section{Making the best of a bad situation}

Ward et al. (9) report that under hypoxic conditions, an alternative promoter located in the first intron of the NOS1 gene directs the transcription of mRNA species lacking 5 '-untranslated sequences encoded by exon 1 , which when present inhibit the translation of nNOS mRNA into protein, especially under hypoxic conditions (Figure 1A). Thus, the synthesis of an mRNA species that escapes translational repression allows efficient synthesis of nNOS protein in hypoxic cells. A similar strategy of alternative promoter utilization has been reported for the VEGF gene (12). Ward et al. also generated transgenic mice in which $l a c Z$ coding sequences were under the control of a $2.5-\mathrm{kb}$ Nos1 genomic region upstream of the translation initiation site. When these mice were exposed to chronic ambient hypoxia $\left(8 \% \mathrm{O}_{2}\right.$ for 48 hours), arterial expression of $\beta$-galactosidase was induced (9).

With the delineation of the cis-acting sequences controlling hypoxia-induced expression of nNOS, attention will turn to the identification of trans-acting factors. Hypoxia-inducible factor-1 (HIF-1) regulates the expression of VEGF as well as hundreds of other genes in response to hypoxia (13), including NOS2 $(7,8)$. Ward et al. (9) report the presence of potential HIF-1 binding sites within the NOS1 genomic sequences that were sufficient for hypoxia-inducible lac $Z$ expression. Chromatin immunoprecipitation assays can be performed to investigate whether HIF-1 binds to specific sites in the NOS1 gene in response to hypoxia.

\section{NO synthase performance: $\mathrm{O}_{2}$ does matter}

Even more intriguing is the significance of nNOS protein synthesis under hypoxic conditions. NO synthase (NOS) catalyzes the reaction of arginine plus $\mathrm{O}_{2}$ to yield citrulline plus NO. The apparent $K_{m}$ s of eNOS, iNOS, and nNOS allow for NO production over a 2-log range of $\mathrm{O}_{2}$ concentrations (ref. 14; Table 1), which provides important insight into the physiological functions of the NOS isoforms. The eNOS isoform has a low $K_{m}$ for $\mathrm{O}_{2}$, which insures that the enzyme will remain active in endothelial cells that are invading hypoxic tissue during angiogenesis. In contrast, the high $K_{m}$ of nNOS suggests that even modest reductions in
$\mathrm{O}_{2}$ concentration will result in a significant loss of enzyme activity and there is a linear relationship between $\mathrm{O}_{2}$ concentration and nNOS activity over the entire physiological range (15). These results suggest that the generation of NO by nNOS may represent a signal transduction mechanism in which signal intensity is directly related to $\mathrm{O}_{2}$ concentration. For example, $\mathrm{O}_{2}$-dependent $\mathrm{NO}$ production inhibits sensory discharge from the carotid body under normoxic conditions (16). The fruit fly Drosophila melanogaster also utilizes NO signaling for a variety of adaptive responses to hypoxia (17).

\section{Homeostasis: respond and reset}

These properties of nNOS enzyme activity and gene regulation lead to a paradoxical situation in which hypoxia induces increased synthesis of nNOS protein, which has reduced activity due to substrate deprivation. Indeed, Ward et al. show that nNOS protein levels increased approximately 10fold (see Figure 4 in ref. 9), whereas NOS activity increased less than 1.5-fold (see Figure 3 in ref. 9) in the aortae of rats subjected to hypoxia. The data suggest a homeostatic mechanism (Figure 1B) by which acute hypoxia induces vasoconstriction, which is attenuated under conditions of chronic exposure to hypoxia $(9,18)$. During acute hypoxia, vascular nNOS activity and $\mathrm{NO}$ levels decline due to the combined effect of decreased translation of exon 1-initiated nNOS mRNA into protein and decreased enzyme activity due to substrate $\left(\mathrm{O}_{2}\right)$ deprivation, leading to an acute increase in vasomotor tone. This acute response is followed by the induction of an alternative nNOS mRNA isoform that is not subject to hypoxia-induced translational inhibition, leading to increased nNOS protein levels, increased nNOS activity, and attenuated vasoconstriction. Attenuation of the response under conditions of chronic stimulation is an important characteristic of many homeostatic systems (Figure 1C). The delineation of this feedback circuit provides both an elegant illustration of the complex mechanisms that mediate adaptive responses to hypoxia and a foundation for further analysis of how these responses are dysregulated in the setting of cardiovascular disease.

Address correspondence to: Gregg L. Semenza, 733 North Broadway, Suite 671,
Baltimore, Maryland 21205, USA. Fax: (443) 287-5618; E-mail: gsemenza@jhmi.edu.

1. Ferrara, N. 2004. Vascular endothelial growth factor: basic science and clinical progress. Endocrine Rev. 25:581-611.

2. May, D., et al. 2005. Ero1-La plays a key role in HIF-1mediated pathway to improve disulfide bond formation and VEGF secretion under hypoxia: implication for cancer. Oncogene. 24:1011-1020.

3. Semenza, G.L. 2001. Regulation of hypoxiainduced angiogenesis: a chaperone escorts VEGF to the dance. J. Clin. Invest. 108:39-40. doi:10.1172/ JCI200113374

4. Prabhakar, N.R., and Peng, Y.J. 2004. Peripheral chemoreceptors in health and disease. J. Appl. Physiol. 96:359-366.

5. Halliwill, J.R. 2003. Hypoxic regulation of blood flow in humans: skeletal muscle circulation and the role of epinephrine. Adv. Exp. Med. Biol. 543:223-236

6. Ortiz, P.A, and Garvin, J.L. 2003. Cardiovascular and renal control in NOS-deficient mouse models [review]. Am. J. Physiol. 284:R628-R638.

7. Melillo, G., et al. 1995. A hypoxia-responsive element mediates a novel pathway of activation of the inducible nitric oxide synthase promoter. J. Exp. Med. 182:1683-1693.

8. Palmer, L.A., Semenza, G.L., Stoler, M.H., and Johns, R.A. 1998. Hypoxia induces type II NOS gene expression in pulmonary artery endothelial cells via HIF-1. Am. J. Physiol. 274:L212-L219.

9. Ward, M.E., et al. 2005. Hypoxia induces a functionally significant and translationally efficient neuronal NO synthase mRNA variant. J. Clin. Invest. 115:3128-3139. doi:10.1172/JCI20806.

10. Koumenis, C., et al. 2002. Regulation of protein synthesis by hypoxia via activation of the endoplasmic reticulum kinase PERK and phosphorylation of the translation initiation factor eIF-2 $\alpha$. Mol. Cell Biol. 22:7405-7416.

11. Stein, I., et al. 1998. Translation of vascular endothelial growth factor mRNA by internal ribosome entry: implications for translation under hypoxia. Mol. Cell. Biol. 18:3112-3119.

12. Akiri, G., et al. 1998. Regulation of vascular endothelial growth factor (VEGF) expression is mediated by internal initiation of translation and alternative initiation of transcription. Oncogene. 17:227-236.

13. Manalo, D.J., et al. 2005. Transcriptional regulation of vascular endothelial cell responses to hypoxia by HIF-1. Blood. 105:659-669.

14. Stuehr, D.J., Santolini, J., Wang, Z.Q., Wei, C.C., and Adak, S. 2004. Update on mechanism and catalytic regulation in the NO synthases. J. Biol. Chem. 279:36167-36170.

15. Elayan, I.M., Axley, M.J., Prasad, P.V., Ahlers, S.T., and Auker, C.R. 2000. Effect of hyperbaric oxygen treatment on nitric oxide and oxygen free radicals in rat brain. J. Neurophysiol. 83:2022-2029.

16. Prabhakar, N.R. 1999. NO and CO as second messengers in oxygen sensing in the carotid body. Respir. Physiol. 115:161-168.

17. Wingrove, J.A., and O'Farrell, P.H. 1999. Nitric oxide contributes to behavioral, cellular, and developmental responses to low oxygen in Drosophila. Cell. 98:105-114.

18. Earley, S., and Walker, B.R. 2003. Increased nitric oxide production following chronic hypoxia contributes to attenuated systemic vasoconstriction. Am. J. Physiol. 284:H1655-H1661. 